\title{
Pulmonary veno-occlusive disease of presumably intrauterine origin
}

\author{
C. A. WA GENVOORT, G. LOSEKOOT, and E. MULDER \\ Laboratory of Pathological Anatomy and Section of Paediatric Cardiology, University of Amsterdam, \\ and the Nicolaas Tulp Hospital, Amstelveen, Netherlands
}

\begin{abstract}
A case is presented of a male infant aged 8 weeks at the time of his death with pulmonary veno-occlusive disease. Almost all pulmonary veins and venules were narrowed or obstructed by intimal fibrosis with such a pronounced deposition of collagen and elastic tissue that an intrauterine origin of these lesions appeared likely. Bronchial veins and anastomoses between pulmonary and bronchial veins were also affected.

The vascular changes were of a thrombotic nature. The presence of subacute myocarditis and chronic interstitial pneumonia suggested that an infection may have caused these alterations. An upper respiratory infection in the mother during her pregnancy may be significant, but several serological titres in the maternal blood were too low to give a clue to the nature of the infection.
\end{abstract}

Veno-occlusive disease of the lung is a rare condition. Its characteristic lesion is narrowing or obliteration of small pulmonary veins and venules. Patients affected by this disease in due course develop chronic pulmonary venous hypertension and death may result from right heart failure. Only 11 acceptable cases have been reported in detail; nine of these have been summarized by Brown and Harrison (1966); the other two patients were described by Weisser, Wyler, and Gloor (1967) and Tingelstad, Aterman, and Lambert (1969). In addition, some cases have been briefly mentioned in abstract form (Liebow, McAdams, Carrington, and Viamonte, 1967).

The present case of a male infant aged 8 weeks is of interest not only because he is the youngest patient with this disease on record but also because it is likely that the process started during intrauterine life.

\section{CASE REPORT}

A male infant was admitted at the age of 39 days to the Tulp Hospital at Amstelveen (Holland) with the following history.

He was born after a full-time pregnancy; delivery had been uneventful. From the 34th week of pregnancy the mother had an upper respiratory infection persisting for several weeks, with cough and rhinitis. Since birth a slight dyspnoea had been noted and feeding had been difficult; the weight of the infant had dropped from $4,150 \mathrm{~g}$ at birth to $4,040 \mathrm{~g}$ at the time of admission. There was no family history of cardiac disease.
Physical examination Dyspnoea and slight cyanosis were present at rest. Pulse rate was $172 / \mathrm{min}$; respiratory rate $90 / \mathrm{min}$; temperature $37^{\circ} \mathrm{C}$. The heart was not enlarged. The second heart sound was loud and narrowly split. No murmurs were audible. The lungs were clear on percussion and auscultation. The liver and the spleen were palpable $4 \mathrm{~cm}$ and $1.5 \mathrm{~cm}$ below the costal margin, respectively.

An electrocardiogram showed right ventricular hypertrophy. Radiographs showed that the heart was of normal size and configuration. The lungs showed a reticular pattern (Fig. 1).

LABORATORY INVESTIGATIONS Urinalysis was normal. $\mathrm{Hb} 11.5 \mathrm{~g} / 100 \mathrm{ml}$; leucocytes $16,400 / \mathrm{mm}^{3}$; differential count normal ; E.S.A. $4 \mathrm{~mm} / 1$ hour ; SGOT 14 units ; SGPT 6 units; LDH 333 units; pH 7.35; $\mathrm{PCO}_{2}$ $50 \mathrm{mmHg}$; standard bicarbonate $25.2 \mathrm{mEq} / 1$; ; actual bicarbonate $27 \cdot 3 \mathrm{mEq} / 1$; ; base excess $+1 \cdot 0$.

Heart failure was diagnosed and the child was treated with digitalis. To improve the general condition $60 \mathrm{ml}$ of whole blood was transfused and further cardiac investigations were performed (Binnengasthuis, University Hospital, Amsterdam).

HEART CATHETERIZATION (RIGHT-SIDED) (Table) The pressure in the right ventricle and pulmonary artery was very high; the pulmonary wedge pressure was only slightly raised; the pressure in the left atrium was low. The oxygen saturation of the blood in the right side of the heart was extremely low.

ANGIOCARDIOGRAPHY Left atrial injection disclosed no abnormality; the coronary arteries were normal. Injection in the right ventricle showed a dilatation of the pulmonary trunk; there was a slight reflux 


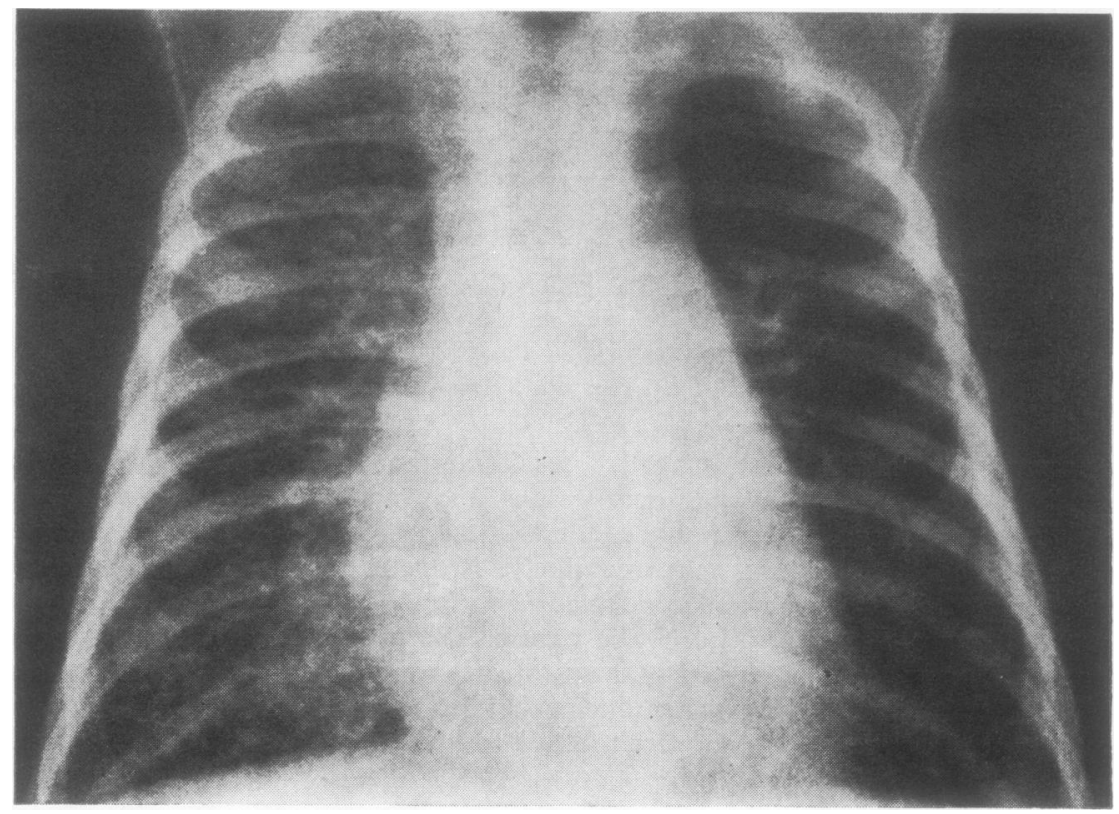

FIG. 1. Chest radiograph showing reticular pattern of lungs.

T A B L E

HEART CATHETERIZATION DATA

\begin{tabular}{|c|c|c|c|c|c|c|c|c|c|}
\hline & IVC & sve & $\mathbf{R A}$ & $\mathbf{R V}$ & PA & PA-wedge & LA & PV & $\begin{array}{c}\text { Femoral } \\
\text { Artery }\end{array}$ \\
\hline Mean pressure $(\mathrm{mmHg})$ & $\dot{3}$ & $\overline{1}$ & $\dot{0}$ & $120-0$ & $110-45$ & $1 \overline{5}$ & $\overline{3}$ & 4 & - \\
\hline $\mathrm{O}_{2}$ saturation $(\%)$ & 31 & 35 & $30-37$ & 32 & 35 & - & 91 & 100 & 91 \\
\hline
\end{tabular}

to the right atrium. In the second phase there was normal filling of the pulmonary veins and left atrium.

A diagnosis of essential pulmonary hypertension was considered. The general condition of the infant deteriorated rapidly; he was very dyspnoeic, pale, and cyanotic and had to be fed by gavage. The haemoglobin content of the blood dropped within a few days from 11.6 to $8.7 \mathrm{~g} / 100 \mathrm{ml}$. The reticulocytes increased to $45 \%$ and the leucocytes to $56,700 /$ $\mathrm{mm}^{3}$ with a shift to the left. The weight of the infant increased from 4,300 to $4,600 \mathrm{~g}$; this increase, probably caused by oedema, was not sufficient to account for the drop in haemoglobin content. As blood loss could not be demonstrated, pulmonary hemosiderosis was considered and prednisone was administered. Despite this therapy the infant died aged 57 days.

\section{NECROPSY}

Necropsy was performed by Dr. E. L. Frensdorf (Amsterdam) and revealed the following relevant findings. The heart was enlarged (weight $30 \mathrm{~g})$ with right ventricular hypertrophy and marked dilatation of the right atrium. There wereo no congenital malformations. The foramen ovale was probe patent but valvular competent; the ductus arteriosus was closed. The pulmonary veins entered the left atrium in a normal way and were? patent in this area. The heart valves were all normal. The lungs contained air and appeared N్ somewhat enlarged but were otherwise normal $\sigma$ on gross examination. On cut section their consistency was tough and there were some small $\frac{\bar{D}}{\square}$ haemorrhagic areas. The liver (weight $400 \mathrm{~g}$ ) and spleen (weight $20 \mathrm{~g}$ ) were congested. Permission 0 for opening the skull was not given. The heart-웅 lung specimen and other material were sent to

us for further investigation.
Microscopic examination of the heart showed $\frac{\stackrel{\Phi}{\Phi}}{\sigma}$ several small foci of degenerated or necrotic heart muscle fibres with infiltration of polymorpho- 
nuclear and some mononuclear cells, occasionally with some fibrosis (Fig. 2). Foci were present in the myocardium of the left and right ventricles as well as in the interventricular septum. The coronary arteries were normal.

Both lungs were congested and showed marked haemosiderosis. In the alveolar spaces there were numerous alveolar macrophages. The alveolar walls were thickened with marked proliferation of fibroblasts and with infiltration by lymphocytes and plasma cells (Fig. 3). Similar infiltrates were present in the peribronchial and interlobular connective tissue. In the left lower lobe there was an extensive area of acute bronchopneumonia. Everywhere else the mucosa of bronchi and bronchioles was normal. An extensive search for toxoplasma in the lung tissue, heart muscle, and lymph nodes remained negative.

The muscular pulmonary arteries were very thick-walled with extension of medial muscle tissue along numerous very small arterioles. The

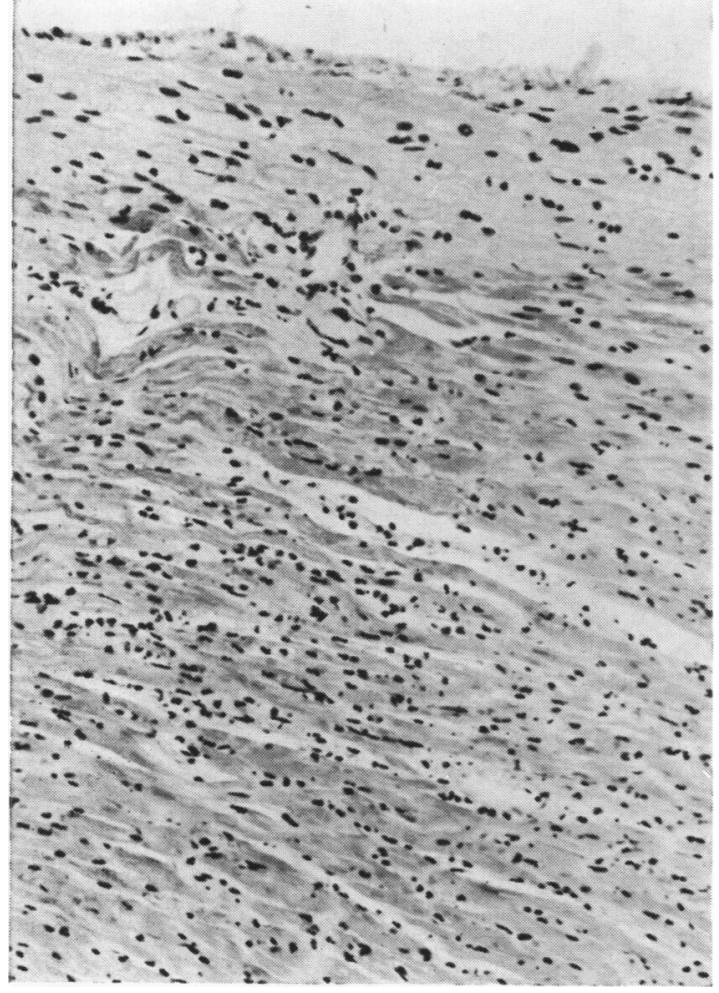

FIG. 2. Myocardium with focus of necrotic heart muscle fibres and infiltration by predominantly polymorphonuclear cells (Haematoxylin and eosin, $\times 60$ ).

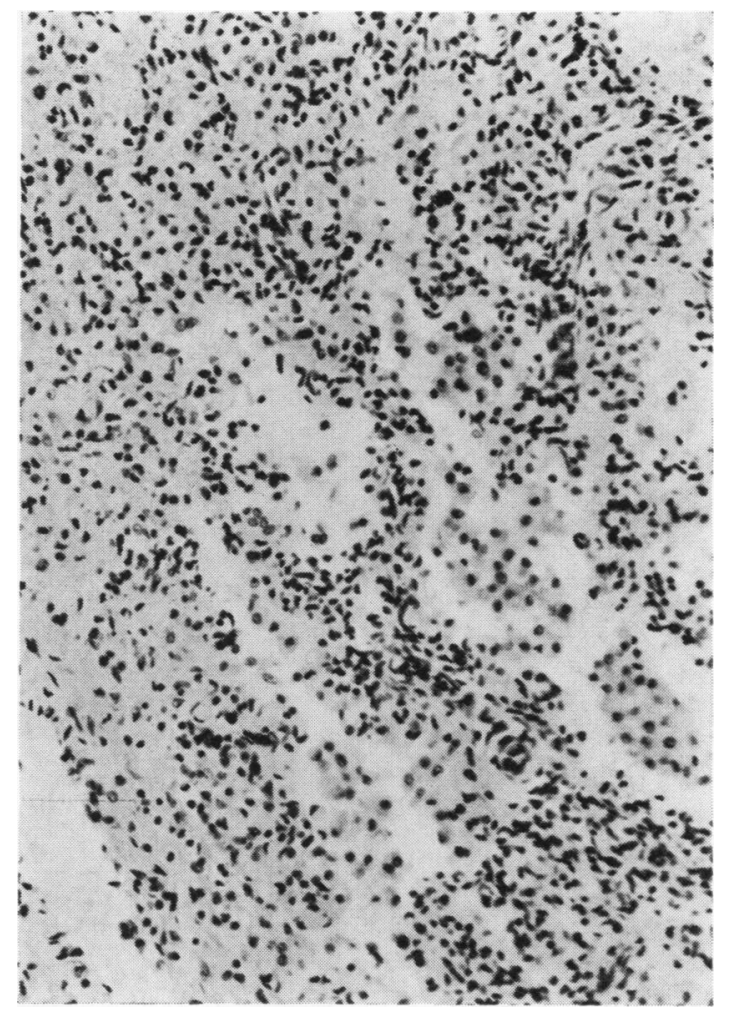

FIG. 3. Lung tissue with thickening of alveolar walls and interstitial pneumonia (Haematoxylin and eosin, $\times 150$ ).

thickness of the media of 50 muscular pulmonary arteries was measured and expressed as a percentage of the external diameter of the vessels. The average value was $21.5 \%$; the normal figure for infants of this age is in the range of $10 \%$ (Wagenvoort, Neufeld, and Edwards, 1961). There were no intimal lesions and no thrombi in the pulmonary arteries.

The pulmonary venous system was entirely abnormal. Almost all veins and venules in the sections showed irregular intimal thickening, either by loose paucicellular or by dense connective tissue, rich in collagenous and elastic fibres (Fig. 4). The lesions were crescent-shaped, cushionlike or in the form of irregular thick septa dividing the lumen in several compartments (Fig. 5). Total obliteration of the lumen was common. The lesions were also present in large pulmonary veins even close to the hilar region. At the level of the bronchi the intimal fibrosis extended by way of numerous venous anastomoses into prominent bronchial veins and many veins in the 


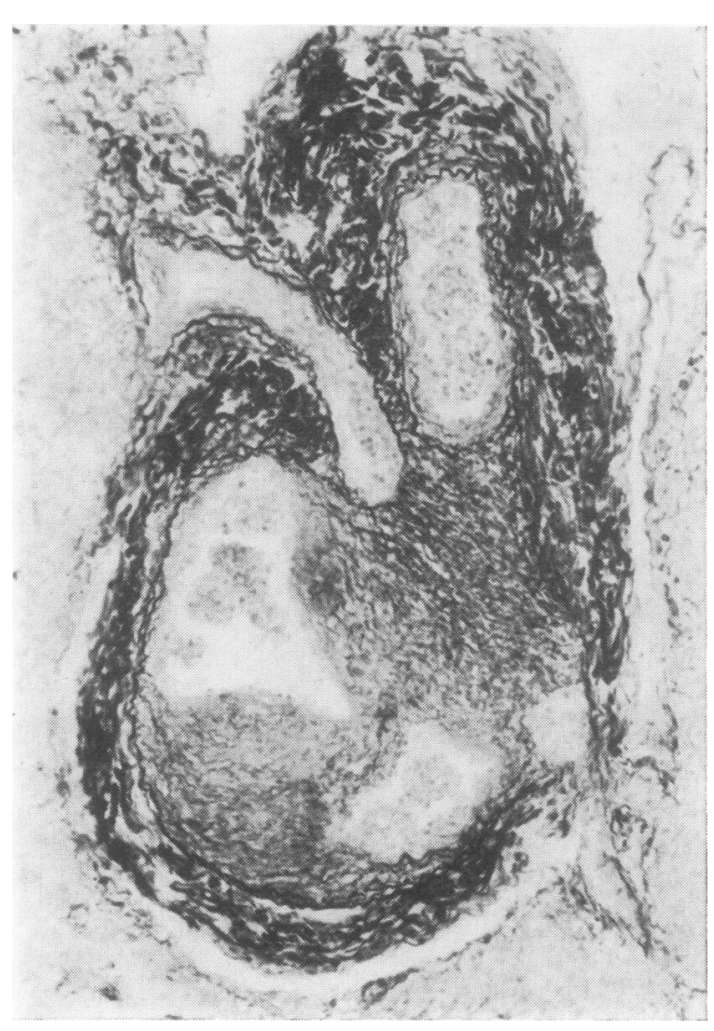

FIG. 4. Pulmonary vein with partial obliteration by fibrous tissue with dense collagen and elastic fibres. There is recanalization (Elastic-van Gieson stain, $\times 100$ ).

bronchial mucosa were equally narrowed or obliterated (Fig. 6). The media of the pulmonary veins was usually somewhat thicker than normal but arterialization, that is the development of internal and external elastic laminae producing the appearances of pulmonary arteries, was always distinct (Fig. 7).

The bronchial arteries were normal. They were traced in serial sections to establish the eventual presence of arterial anastomoses, but no bronchopulmonary arterial anastomoses could be found. There were only occasional bronchopulmonary and pulmobronchial arteries. There was clearly no increase in the number of these vessels as compared to those in normal infants (Wagenvoort and Wagenvoort, 1967). The histological sections of other organs were unremarkable except for congestion. No thrombi or other vascular lesions in any of the systemic arteries or veins were observed.
Samples of the infant's blood were not available after the postmortem diagnosis had been established, but a sample of the maternal blood was taken three weeks after the infant's death, that is 11 weeks after birth. Serological reactions (complement fixation) for adenoviruses were negative ; for enteroviruses (with ECHO 9 antigen) the titre was $1 / 32$, for measles $1 / 16$, for mumps $1 / 8$, and for toxoplasmosis $1 / 128$.

\section{DISCUSSION}

Changes in the intrapulmonary veins, including intimal fibrosis, are commonly seen in patients of all ages with chronic pulmonary venous hypertension due to mitral or aortic valvular disease, congenital aortic atresia or chronic left heart failure (Wagenvoort, 1970). In the absence of cardiac lesions, narrowing or obstruction of pul- $\stackrel{\bigodot}{<}$ monary veins by intimal fibrosis as a condition $\vec{\omega}$ sui generis is very rare. Among the 11 patients

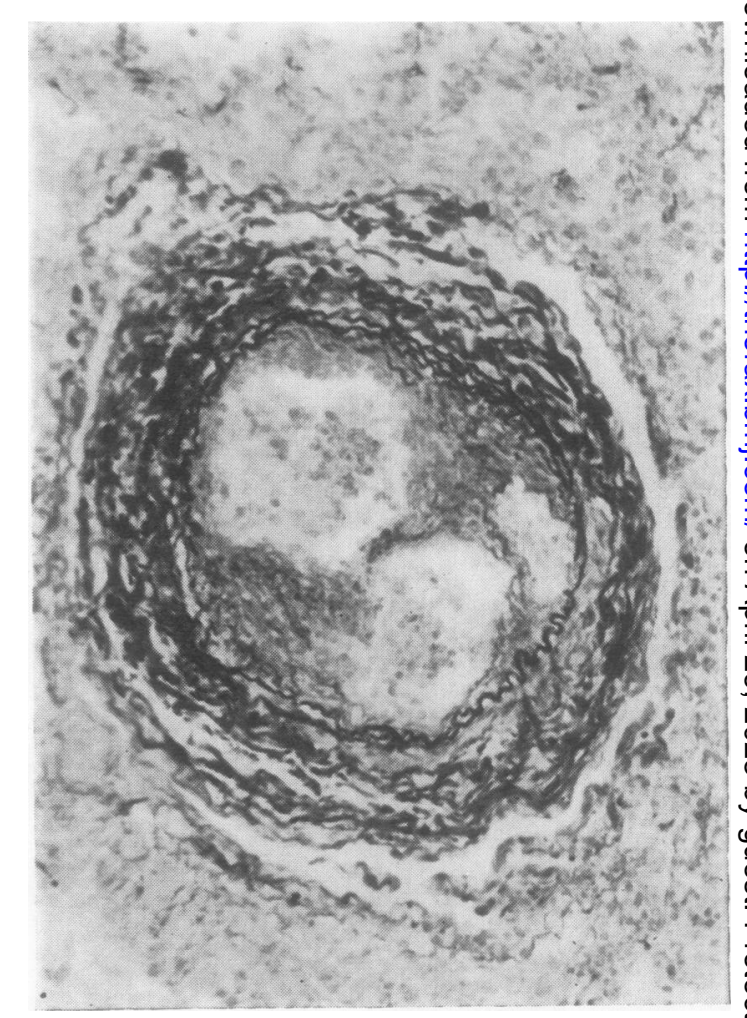

FIG. 5. Pulmonary vein with intraluminal septa due to recanalization of organized thrombus (Elastic-van Gieson stain, $\times 200$ ). 


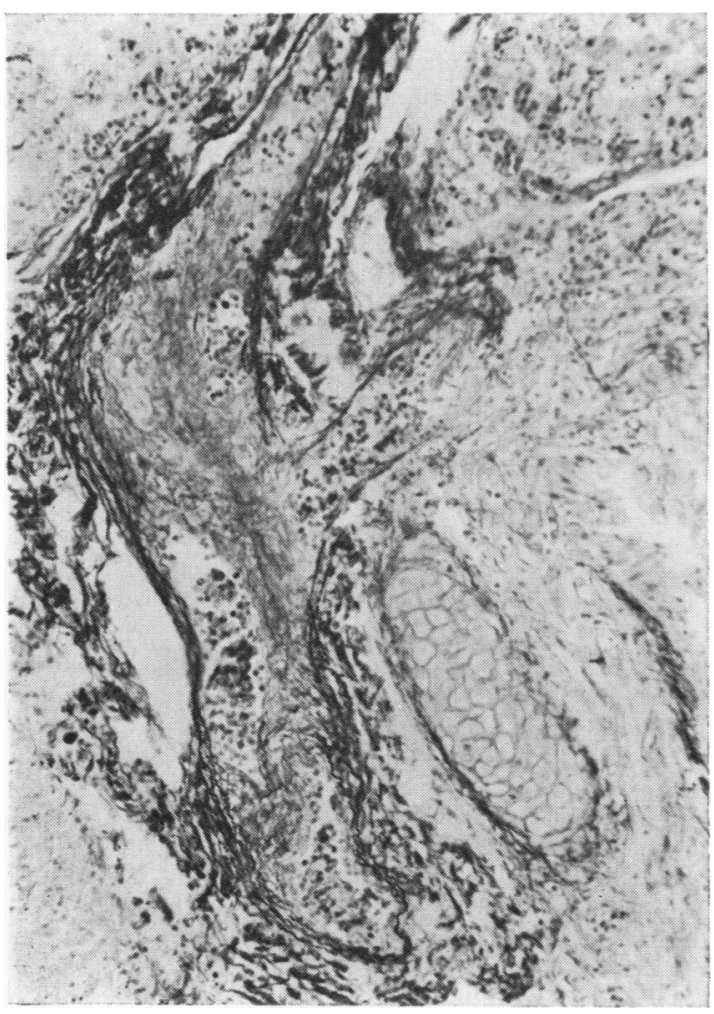

FIG. 6. Anastomosis between pulmonary vein and bronchial vein; the latter is penetrating the bronchial mucusa. The anastomosis is obliterated (Elastic-van Gieson stain, $\times 150)$.

reported in the literature with this so-called pulmonary veno-occlusive disease, there were three adults and eight children up to the age of 16 years. The youngest patient was an infant of 21 months described by Tingelstad et al. (1969). Seven patients were male and four female.

Our patient was only 8 weeks old at the time of death and was symptomatic from the first week of life onward. Not only is this infant the youngest patient known to have suffered from this disease, but clinical and morphological evidence suggest that the process started during intrauterine life.

The obstructive lesions in the pulmonary veins are in this case certainly of thrombotic origin. In numerous veins thrombi in all stages of organization and recanalization were observed, sometimes with recent thrombi in addition. The formation of intraluminal fibrous septa, which were numerous in both the large and small pulmonary veins of this patient, is always an indication of a thrombotic process and is due to exces-

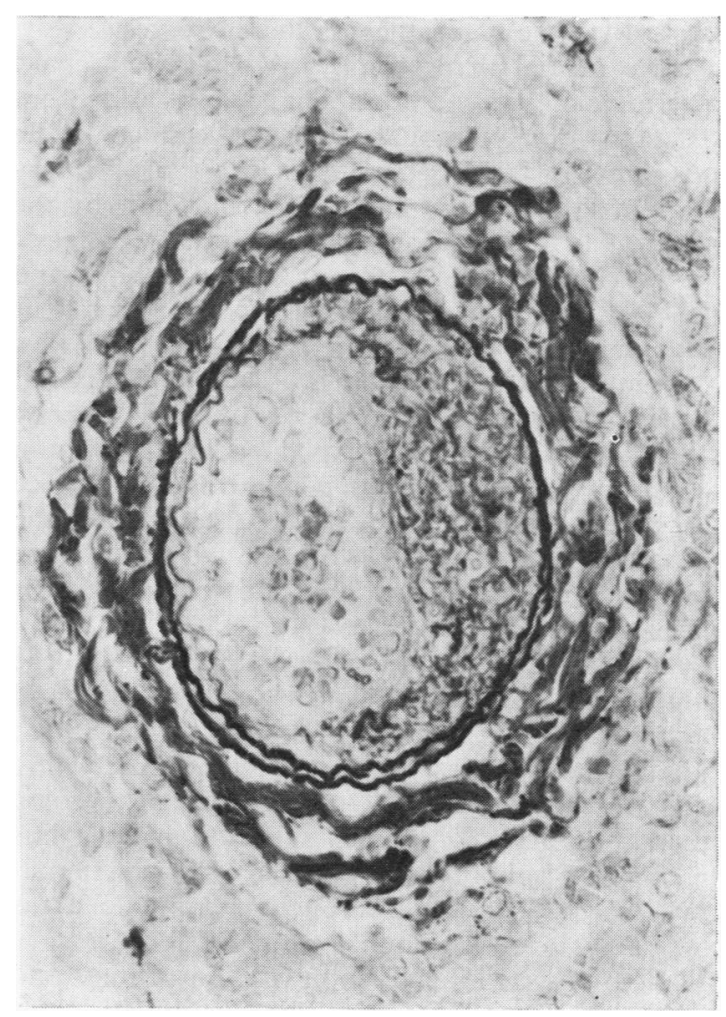

FIG. 7. Pulmonary venule with crescent-shaped intimal fibrosis. At one side there is arterialization of the vascular wall (Elastic-van Gieson, $\times 500$ ).

sive recanalization. Similar septa are known to occur in pulmonary arteries in cases of cyanotic congenital heart disease (Rich, 1948) and of chronic pulmonary thromboembolism (Wagenvoort and Wagenvoort, 1970).

It has been suggested by several authors (Stovin and Mitchinson, 1965; Brown and Harrison, 1966 ; Heath, Segel, and Bishop, 1966; Liebow et al., 1967) that thrombosis is basic to the pulmonary venous lesions in cases of pulmonary veno-occlusive disease, and in most reports the occurrence of recognizable thrombi, recent or in the process of organization within the pulmonary veins, is mentioned.

In our case, the thrombotic lesions in the veins were in part characterized by a deposition of dense, closely packed collagenous and elastic fibres, making it highly improbable that the process of organization was of less than eight weeks' duration. An intrauterine origin of the process, although with subsequent expansion after birth 
up to the time of death, was therefore very likely.

The medial hypertrophy of the pulmonary arteries can be readily explained as being secondary to the pulmonary venous changes. The possibility of this being an example of primary pulmonary hypertension can be ruled out by the nature and distribution of the vascular changes.

The considerable degree of haemosiderosis and the dilatation of many lymphatics is consistent with congestion in the pulmonary capillaries. That in these circumstances the pulmonary arterial wedge pressure is not, or as in our case is only slightly raised has been explained by Carrington and Liebow (1970). They pointed out that, once the arterial inflow is blocked by the catheter, the pressure distal to the catheter will fall since the intervenous connexions are obstructed or narrowed.

It has been suggested that infection is the underlying cause for this disease (Brewer and Humphreys, 1960; Crane and Grimes, 1960; Stovin and Mitchinson, 1965 ; Heath et al., 1966; Liebow et al., 1967). The presence of chronic interstitial pneumonia and subacute myocarditis in our case supports the concept of an inflammatory origin. The acute bronchopneumonic areas are likely to be a terminal complication.

As to the aetiology, both viral infections and toxoplasmosis can cause this combination of neonatal myocarditis and pneumonia. Stovin and Mitchinson (1965) suggested a toxoplasmic aetiology in their case of pulmonary veno-occlusive disease, although the titres were not high enough to be diagnostic. In our case only serological data in the mother were available, but the relatively low titre for toxoplasmosis made a recent infection appear unlikely. Since also an extensive search for parasites in the organs (particularly the myocardium and lungs) remained negative, we believe that toxoplasmosis as a causative agent can be virtually excluded. The serological titres in the maternal blood were negative for adenoviruses and inconclusive for enteroviruses, a titre of $1 / 32$ being not uncommon in healthy adults. Unfortunately, assessment or serological reactions for Coxsackie group B, which not infrequently causes myocarditis and pneumonia, is technically extremely difficult and unreliable, since normal ranges are unknown. These reactions were, there- fore, not tested in this case; these viruses, however, cannot be excluded as a possible aetiological agent, also in view of the upper respiratory infection of long duration suffered by the mother in the latter part of pregnancy.

Although pulmonary veno-occlusive disease is a distinct clinicopathological entity, it is possible that it may be caused by various infectious agents.

We are grateful to Dr. E. L. Frensdorf, Amsterdam, for submitting the necropsy specimen to us, to Professor F. Dekking and Dr. K. W. Slaterus, Amsterdam, for their help with the serological reactions, and to Miss H. J. Dijk for technical assistance.

\section{REFERENCES}

Brewer, D. B., and Humphreys, D. R. (1960). Primary pulmonary hypertension with obstructive venous lesions. Brit. Heart J., 22, 445.

Brown, C. H., and Harrison, C. V. (1966). Pulmonary veno-occlusive disease. Lancet, 2, 61.

Carrington, C. B., and Liebow, A. A. (1970). Pulmonary veno-occlusive disease. Hum. Path., 1, 322.

Crane, J. T., and Grimes, O. F. (1960). Isolated pulmonary venous sclerosis: a cause of cor pulmonale. J. thorac. cardiovasc. Surg., 40, 410.

Heath, D., Segel, N., and Bishop, J. (1966). Pulmonary veno-occlusive disease. Circulation, 34, 242.

Liebow, A. A., McAdams, A. J., Carrington, C. B., and Viamonte, M. (1967). Intrapulmonary veno-obstructive disease. Circulation, 35-36, suppl. II, 172.

Rich, A. R. (1948). A hitherto unrecognized tendency to the development of widespread pulmonary vascular obstruction in patients with congenital pulmonary stenosis (Tetralogy of Fallot). Bull. Johns Hopk. Hosp., 82, 389.

Stovin, P. G. I., and Mitchinson, M. J. (1965). Pulmonary hypertension due to obstruction of the intrapulmonary veins. Thorax, 20, 106.

Tingelstad, J. B., Aterman, K., and Lambert, E. C. (1969). Pulmonary venous obstruction. Amer. J. Dis. Child., 117, 219.

Wagenvoort, C. A. (1970). Morphologic changes in intrapulmonary veins. Hum. Path., 1, 205.

Neufeld, H. N., and Edwards, J. E. (1961). The structure of the pulmonary arterial tree in fetal and early postnatal life. Lab. Invest., 10, 751.

- and Wagenvoort, N. (1967). Arterial anastomoses, bronchopulmonary arteries, and pulmobronchial arteries in perinatal lungs. Lab. Invest., 16, 13.

- (1970). Primary pulmonary hypertension. A morphologic and morphometric study of 156 cases. Circulation. 42, 1163.

Weisser, K., Wyler, F., and Gloor, F. (1967). Pulmonary veno-occlusive disease. Arch. Dis. Childh., 42, 322. 